\title{
MOTIF BATIK SRI TANJUNG KARYA HADI SUMARNO INDRAGIRI HILIR RIAU DALAM PERSPEKTIF ESTETIKA
}

\author{
Rusman Yatim \\ Mahasiswa pasca sarjana ISI Padang Panjang
}

\begin{abstract}
The research entitled Batik Motives Sri Tanjung by Hadi Sumarno from Indragiri Hilir Riau in Aesthetic Perspective, it analyzes the exixtence, development, meaning and aesthetical creation of the motives. The main purpose of this reseach is to find the philosophical meaning of the motives creation and will be described deeply, and widely based on the aesthetic theory perspective.
\end{abstract}

Keywords: Batik Motive, Estetic, Batik Sri Tanjung

\section{LATAR BELAKANG}

Pengkajian tentang "Motif
Batik" sangatlah menarik dalam pengembangan ilmu pengetahuan khususnya "Seni Kriya Indonesia Kekinian". Karena ketertarikan inilah penulis mengkaji tentang "Motif Batik Sri Tanjung Karya Hadi Sumarno Indragiri Hilir Riau Dalam Perspektif Estetika". Dalam perwujudannya unsur motif atau ragam hias merupakan sebuah unsur yang melekat dan terkait erat den-gan aspek keindahan. Keindahan motif tak terbatas secara visual saja, namun juga terkandung nilai atau makna simbolis. Motif merupakan ungkapan tentang cita-cita, maksud, harapan, ajaran, tuntunan dan tujuan tertentu. (Wisetrotomo, 2009: 83).

Secara terstruktur motif batik Sri Tanjung ini awal mulanya di desain oleh Bapak H. Badri ditahun 2009, yang merupakan jenis motif khas Indragiri Hilir, desain motif pertamanya terdiri dari: motif mayang terurai, motif daun pidada, motif kiambang. Desain motif kreasi artistik dikembangkan oleh Hadi Sumarno, salah satunya motif kelapa menjadi 10 (sepuluh) jenis motif yaitu motif kelapa ber-padu, motif mayang terurai, motif kelapa berjajar, kelapa bertuah, motif meulur kelapa, motif umbut kelapa, Motif kelapa seribu parit, motif kelapa tampuk merah, motif sabut kelapa, motif kelapa sagu 
nipah. Pengembangan motif kiambang menjadi 5 (lima) jenis motif, yaitu motif kiambang berkelok, motif kiambang merajut, motif kiambang berpadan, motif kiambang raja, motif kiambang berlapis. Pengembangan jenis motif lainnya yaitu, motif fauna gambut, motif pucuk waluh, motif daun bakau, motif sampan leper, motif menongkah kerang, motif buah pidada. ( $\mathrm{H}$. Badri, Hadi Sumarno Wawancara : oktober 2016).

Penciptaan karya seni desain motif batik Sri Tanjung didasarkan pada aspek georafis fungsionalnya, tetapi juga untuk pemenuhan kebutuhan terhadap keindahan. Salah satunya motif meulur kelapa yang ide penciptaannya terinspirasi dari aktivitas petani pada saat memanen kelapa dikebun, untuk menghemat tenaga dan waktu petani kelapa memanfaatkan aliran parit - parit kecil yang berdiameter 1 (satu) meter yang berada dikebun. Proses pengangkutan kelapa dengan cara menghanyutkan kelapa dari hulu kehilir menuju tempat penampungan kelapa yaitu langkau. Bagi masyarakat Indragiri Hilir petani kelapa menyebutnya "meulur nyiur". Kata nyiur berasal dari bahasa banjar, Kalimantan Selatan, yang artinya kelapa. Penamaan motif ini dinamakan "motif meulur kelapa" oleh bapak Hadi Sumarno. Adapun bentuk kreasi motifnya sebagai berikut :

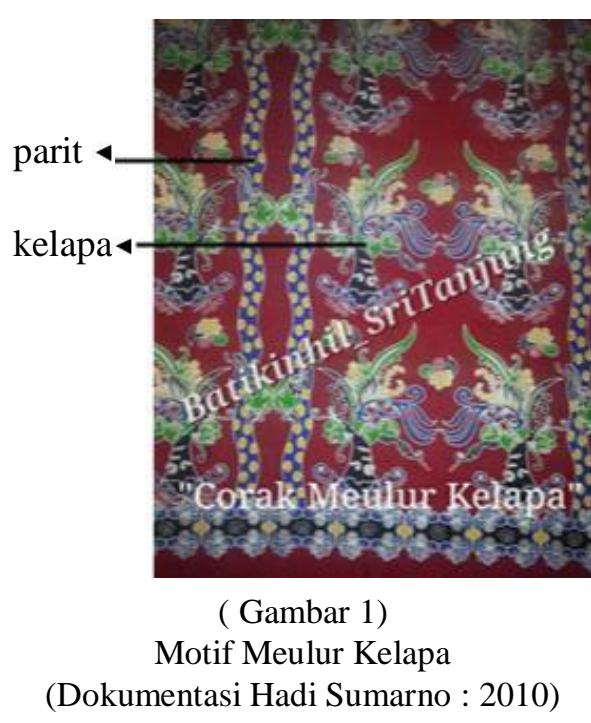

Nilai-nilai kearifan lokal diatas dari ide garapan penciptaan motif meulur kelapa merupakan sistem ide dan aktivitas masyarakat. Menuru Koentraningrat, mengartikan kebudayaan sebagai produk manusia yang wujudnya dapat berupa 1). Kompleks ide-ide, gagasan, nilainilai, norma - norma, peraturan dan sebagainya, 2). Komplek aktivitas dan tindakan berpola dari manusia dalam masyarakat, 3). Benda benda karya manusia. (Yanis 2016 : 2). Analisis ide penciptaan motif 
meulur kelapa poin 1,2 dan 3, merupakan aplikasi identitas karya manusia yang mempunyai nilai filosofi tersendiri dari manusia dan sosial masyarakatnya.

Motif Batik Indragiri Hilir yang penuh khazanah dan nilai his-toris budaya mempunyai pandangan tersendiri dalam babak baru sebuah karya ornamentatif, representatif, pola bentuk, ritme dan warna. Kain batik tidak hanya memiliki nilai estetis yang luhur, namun dibalik motif dan warna mengandung nilainilai simbolis dan filosofis. Objek penelitian ini menggunakan pendekatan pengkajian "teori estetika dan teori bentuk". Bentuk motif ragam kreasi artistik, batik Sri Tanjung merupakan pembahasan utama penelitian ini yang meliputi struktur atau komposisi yang merupakan tata susun yang terdiri dari pengulangan atau susunan pola. Pola terdiri dari motif utama, motif pengisi (selingan) dan motif isian. (Kartika, 2016: 77).

Batik Sri Tanjung pimpinan $\mathrm{H}$. Badri merupakan bagian kelom-pok masyarakat pekerja seni yang berdiri dari tahun 2009 - hingga sekarang. Pengrajin batik ini awalnya mendapat pelatihan dari Binaan
Dewan Kerajinan Nasional Daerah Kabupaten Indragiri Hilir. Selanjutnya, dalam pembinaan tersebut para pekerja seni dipondokkan atau dimagangkan di daerah Yogyakarta Balai Besar Batik Indonesia. Berkat ilmu membatik Alhamdulillah "Batik Sri Tanjung" didirikan dan berkembang hingga hari ini. (Hadi Sumarno Wawancara : November 2016).

\section{KONSEP}

Kerangka teoritis ini menggunakan pendekatan Estetika dan pendekatan bentuk dalam menganalisis objek kajian. Bentuk (form) adalah totalitas dari pada karya seni, bentuk merupakan organisasi atau satu kesatuan atau komposisi dari unsur-unsur pendukung karya. Ada dua macam bentuk, yaitu Visual Form yaitu bentuk fisik dari sebuah karya seni atau satu kesatuan dari unsur-unsur pendukung karya seni tersebut. Spesial Form yaitu bentuk yang tercipta karena ada hubungan timbal balik antara nilai-nilai yang dipancarkan oleh fenomena ben-tuk fisiknya terhadap tanggapan kesadaran emosionalnya.

Berdasarkan pengkajian bentuk visual atau visual form dan teori 
bentuk Dharsono mengkaitkannya dengan shape, stilisasi, distorsi, transformasi dan disformasi. Secara garis besar struktur ornamen dapat dibedakan menjadi tiga hal utama yaitu Garis -garis berkesinambun-gan dengan segala variasinya, yaitu berupa garis-garis lurus, garis patah, garis lengkung, garis bergelombang, dan juga garis-garis yang berfungsi sebagai garis batas. Berupa bentukbentuk figur yang berkelompok. Bentuk hiasan yang menyeluruh dan utuh, menutup seluruh wujud dari bentuk yang dikenai, dengan jali-nan yang saling mengikat terpadu, berhubungan antara satu dengan bentuk lainnya, saling berdekatan secara berulang-ulang. Sebenarnya garis yang berkesinambungan, garis lurus, monochrome yang biasa digunakan untuk membuat garis pembatas, seperti garis-garis tegak lurus, adalah termasuk dalam unsurunsur desain. Pada awalnya garisgaris semacam ini telah ada dengan berbagai variasinya. Misal-nya : garis putus-putus, garis patah, garis zigzag, garis berlika-liku, dan sebagainya.

\section{METODE PENELITIAN}

Metode penelitian ini akan mengkaji permasalahan bentuk kreasi artistik estetis motif batik Sri Tanjung dan keberadaan batik Sri Tanjung melalui penelitian kualitatif. Adapun teknik pengambilan data penelitian yaitu dengan teknik survey, observasi lapangan kelokasi penelitian ini, Sasaran Penelitian ini, Peneliti membatasi pada permasalahan bentuk kreasi artistik estetis motif batik Sri Tanjung dan keberadaan Batik Sri Tanjung. Objek penelitian dibatasi pada kain batik yang ada di sentra Batik Sri Tanjung yang difokuskan terhadap motif, bentuk. Wilayah Penelitian di fokuskan di Batik Sri Tanjung pencarian artefak bentuk batik berdasarkan tata susun terstruktur berdasarkan bentuk pendekatan teori estetika dan teori bentuk.

\section{PEMBAHASAN}

Menurut Kuswadji, batik berasal dari bahasa Jawa, Mbatik, kata mbat dalam bahasa yang disebut ngembat. Arti kata tersebut melontarkan atau melemparkan. Sedangkan kata tik bisa diartikan titik. Jadi yang dimaksud batik atau mbatik adalah melemparkan titik berkali-kali pada kain.( Batik Barcode, 2010: 3). Secara etimologi istilah batik berasal dari kata yang berakhiran"tik" berasal dari kata 
menitik yang berarti menetes. Berarti menitikkan malam dengan canting sehingga membentuk corak yang terdiri atas susunan titikan dan garisan (Anas etal, 1997: 14). Menurut terminologinya batik adalah gambar yang dihasilkan dengan menggunakan alat canting atau sejenisnya dengan bahan lilin sebagai penahan dengan masuknya warna. Batik sebagai kata benda adalah sehelai kain yang merupakan hasil penggambaran motif dari perintangan malam atau lilin, artinya bahwa malam atau lilin sebagai perintang dalam membentuk motif melalui proses celup rintang warna.

Batik memiliki sejarah dan riwayat yang panjang disetiap wilayah di Nusantara. Kerajinan batik dikenal sejak zaman kerajaan Majapait, batik memiliki perkembangan dan kisah yang menarik. Eksistensi batik pada masa kerajaan Majapahit sebagai kerajaan besar telah membuat tradisi kebudayaan yang mengakar di wilayah Nusantara. Menjadi popular akhir abad XVIII atau awal abad XIX batik yang dihasilkan semuanya batik tulis sampai awal abad XX. Menurut G.P. Roufffaer berpendapat bahwa tehnik batik ini diperkenalkan dari India atau Sri Langka pada awal abad ke VI atau VII. (Prasetyo 2010: 2).

\section{Sejarah Batik Sri Tanjung dan Perkembangannya}

Kerajinan batik Sri Tanjung di Kabupaten Indragiri Hilir Riau berkembang akhir tahun 2009. Awal mulanya dikembangkan oleh bapak H. Badri Suliswanto dengan nama kerajinan batiknya Anugrah Mandiri. Sebelumnya kerajinan batik ini belum ada di Kabupat-en Indragiri Hilir, Alhamdulillah berkat Bapak H. Badri Suliswanto mengembangkan karya seni batik hingga bisa berkembang. Batik adalah salah satu bagian karya budaya bangsa Indonesia hasil perpaduan antara seni dan teknologi. Motif dan warnanya menunjukkan teknologi yang unik dan mengagumkan. Seni batik merupakan perpaduan seni motif dan ragam hias, ketika membatik ada sesuatu yang berbeda, perbedaan itu terletak pada motif dan ragam hias yang diterapkan. Perbedaan ini merupakan heterogen masyarakat yang memiliki latar belakang ekonomi, sosial, budaya, teknologi dan agama. 
Langkah awal pendesain-an motif batik Sri Tanjung ini yaitu motif mayang terurai, motif daun pidada dan motif kiambang yang didesain oleh bapak $H$. Badri Suliswanto. Gagasan penciptaan ide desain ini terinspirasi dari namanama daerah, historis daerah dan flora dan fauna di Kabupaten Indragiri Hilir. Beraneka ragam budaya, suku, agama di Indragiri Hilir yang merupakan identitas khazanah kebangsaan sebagai langkah memajukan industri membatik.

Berkat keterlibatan pemerintah daerah, batik Sri Tanjung berkembang, diperkenalkan melalui lembaga Dewan Kerajinan Nasional Daerah (DEKRANASDA) Kabupaten Indragiri Hilir oleh Ibu Syafni Zuryanti Indra (istri Bupati Indragiri Hilir 2009 - 2014) kepada kalangan aparatur sipil Negara (ASN) lingkungan pemda Indragiri Hilir bulan juni 2010 agar memberdayakan dan membudayakan busana batik Indragiri Hilir. Pempublikasikasian karya seni batik Sri Tanjung ke tingkat nasional dan international melalui pameran, dan Indonesia Ekspo hingga dikenali oleh masyarakat umum khususnya Indragiri Hilir, Riau dan mancanegara.
Pada tahun 2013 dengan berjalannya secara kontiniu kerajinan batik ini akhirnya secara resmi bapak Hadi Sumarno menamakan " Batik Sri Tanjung " sebagai batik Indragiri Hilir Riau dengan SIUP (Surat Izin Usaha) Nomor : 503/ BP2MPD-SIUPDAG/VI2013/370 dari Dinas Penanam Modal dan Pelayanan Terpadu Satu Pintu Kabuapten Indragiri Hilir. Sebelumnya semasa ayah beliau H. Badri Suliswanto diberi nama kerajinan “ Batik Anugrah Mandiri”. Batik Sri Tanjung sudah mendapat nama di hati masyarakat khususnya kota Tembilahan, dan terkenal untuk kalangan masyarakat Kabupaten Indragiri Hilir. Pengembangan batik Sri Tanjung ini mengalami kemajuan pesat dari karya batik tulis hingga batik cap, batik printing, yang diproduksi secara banyak (masal) untuk pembuatan batik batik di sekolah, dari tingkat Raudathul Atfal (RA)/ Taman Kanak - Kanak (TK), Sekolah Dasar (SD)/ Ibtidaiyah, Tsanawiyah/ Sekolah Menengah Pertama(SMP), Aliayah/ Sekolah Menengah Atas (SMA) Perguruan Tinggi dan seragam batik kerja Aparatur Sipil Negara (ASN) yang dipakai setia hari kamis di Kabupaten Indragiri Hilir. 
Salah satu kepedulian Pemerintah dalam mendukung budaya batik sebagai cagar budaya adalah memperkenalkan khazanah budaya kepada masyarakat. Kepedulian itu pun dibuatkan dalam Peraturan Daerah agar para pegawai (aparatur sipil negara) khususnya dilingkungan Kabupaten Indragiri Hilir agar menggunakan (memakai) batik Inhil setiap hari kamis sebagai tren berbudaya batik. tentang batik khas Inhil resmi dipakai pada acara Teknologi Tepat Guna (TTG) untuk tamu undangan yang diresmikan langsung oleh Bapak Gubernur Riau Arsyad Juliandi Rahman sebagai wujud pengembangan kebudayaan akan cinta terhadap batik daerah. Melalui Dewan Kerajinan Nasional Daerah (Dekranasda) Hj. Zulaika Wardan (Ibu Bupati Indragiri Hilir 2014 2018). Batik Sri Tanjung Kabupaten Indragiri Hilir telah mendunia, dari kalangan daerah, nasional dan International yang dibawa oleh pemerintah daerah melalui pameran, pertemuan penting dikalangan pejabat daerah dan pusat dan Indonesia ekspor setiap tahunnya di Jakarta dan pameran antar Negara.

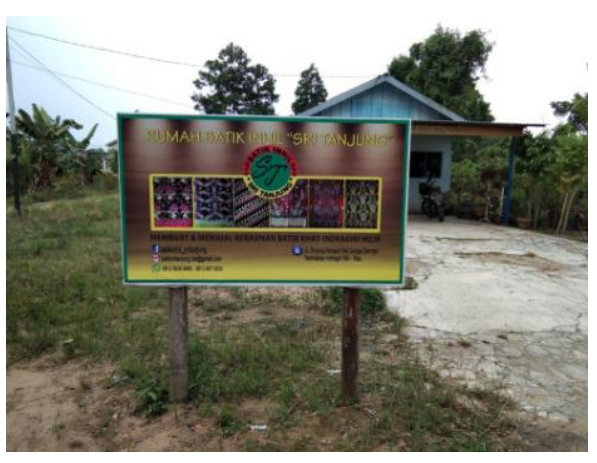

Gambar

Tampak Plang Rumah Batik Sri Tanjung,

(dokumentasi Rusman Yatim : april 2018)

\section{Bentuk Ragam Hias Motif Batik} Sri Tanjung

Secara terstruktur motif batik Sri Tanjung ini awal mulanya di desain oleh Bapak H. Badri ditahun 2009 jenis motif khas Indragiri Hilir, desain motif pertamanya motif mayang terurai, motif daun pidada, motif kiambang. Pada tahun 2010 pak Hadi Sumarno (anak H, Badri) atas permintaan Pemerintah daerah Kabupaten Indragiri Hilir mendesain motif - motif daerah yang menceritakan tentang historis daerah, georafis dan alam Indragiri Hilir dan pantun. Pengembangan desain motif kreasi artistik oleh Hadi Sumarno pun berkembang, salah satunya motif kelapa menjadi 10 (sepuluh) jenis motif yaitu motif kelapa berpadu, motif mayang terurai, motif kelapa berjajar, ke- 
lapa bertuah, motif meulur kelapa, motif umbut kelapa, Motif kelapa seribu parit, motif kelapa tampuk merah, motif sabut kelapa, motif kelapa sagu nipah. Pengembangan motif kiambang menjadi 5 (lima) jenis motif, yaitu motif kiambang berkelok, motif kiambang merajut, motif kiambang berpadan, motif kiambang raja, motif kiambang berlapis. Pengembangan jenis motif lainnya yaitu, motif fauna gambut, motif pucuk waluh, motif daun bakau, motif sampan leper, motif menongkah kerang, motif buah pidada. (H. Badri, Hadi Sumarno Wawancara : oktober 2016).

\section{Jenis Batik Sri Tanjung}

Batik Sri Tanjung Kabupaten Indragiri Hilir Riau merupakan salah satu bagian budaya di Indonesia. Ungkapan ekpresi seni membatik diungkapkan dengan sehelai kain, pemberian motif pada kain yang dimulai dari pemalaman, pewarnaan, sampai pelorodan. Pem-batikan ini memerlukan bahan batik antara lain: lilin, kain, pewarna (remasol), water glass. Jenis batik Sri Tanjung ini dibagi menjadi tiga bagian yaitu sebagai berikut:

\section{Batik Tulis}

Batik tulis merupakan proses pembuatan pola yang dikerjakan dengan menggoreskan malam (lilin) dengan menggu-nakan alat bernama "canting" yaitu semacam wadah yang mempunyai corong pada satu sisinya dan tangkainya dari kayu. Canting ini berisikan cairan malam (lilin) yang kemudian dituliskan sesuai motif pada kain.

\section{Batik Printing}

Batik printing adalah salah satu jenis hasil proses produksi batik yang teknis pembuatannya melalui proses sablon manual (seperti pembuatan spanduk / kaos) atau printing mesin pabrik. Jenis batik printing yang di produksi batik Sri Tanjung.

\section{Batik Cap}

Batik cap dilakukan
dengan cara menggunakan
stempel yang terbuat dari
tembaga, alat tersebut dibasahi
malam pada salah satu sisinya
yang kemu-dian dicapkan pada
kain, hasil batik ini disebut
"batik cap". Cairan malam
yang digores-kan pada kain
tersebut bersifat


melindungi kain cairan warna, bagian yang tertutup malam akan terlindung dari pewarnaan dan membentuk ragam hias setelah proses pelepasan malam (pelorodan). Motif akan mem-bentuk satu kesatuan bentuk yang disebut pola.

\section{KESIMPULAN}

Berdasarkan analisis data kualitatif pengumpulan data secara observasi, dokumentasi, wawancara, studi pustaka terhadap nara sumber, pengkajian dengan topik, Motif Batik Sri Tanjung Karya Hadi Soemarno Indragiri Hilir Riau dalam Perspektif Estetika ini mengkaji keberadaan, perkembangan, makna dan bentuk kreasi artistik estetika yang terkandung dalam motif batik Sri Tanjung. Batik Sri Tanjung yang dikembangkan tahun 2009 hingga sekarang telah berhasil mengembangkan diri pengrajin rumahan menjadi pengrajin sukses dalam mengembangkan batik dalam bentuk karya batik tulis, batik printing, batik cap dan mendapat penghargaan tahun 2015 "Adi Kriya" dari dinas Perindustrian dan Perdagangan Provinsi Riau.

Berdasarkan analisis data geo- grafis alam dan lingkungan Kabupaten Indragiri Hilir merupakan langkah awal penciptaan desain mo-tif batik Sri Tanjung ini yang syarat dengan makna nilai filosofi daerah tempatan tempat penciptaan motif yang diaplikasikan ke seni batik yang bernilai estetis dan reprenstatif. Pengembangan motif, kreasi bentuk motif batik Sri Tanjung hari ini menjadi 21 jenis motif, warna dan nilai estetik yang bermakna. Tata susun motif yang diaplikasikan merupakan bentuk pelestarian dan pengembangan, sumber daya alam dan pranata sosial pada masyarakat Indragiri Hilir Riau.

Kajian Motif batik dalam pendekatan teori estetika dan teori bentuk ini diharapkan memberikan wawasan tentang identitas kebudayaan yang terlukis dalam motif kreasi artistik batik Sri Tanjung yaitu berupa bentuk motif geometris, motif tumbuhan, motif binatang, motif kosmos (motif yang berbentuk alami). Jenis 4 bentuk Batik Sri Tanjung ini memiliki nilai seni budaya Nusantara yang sangat berharga mampu mengangkat derajat budaya daerah dan mampu mengimbangi kepersaingan dunia tekstil di mancanegara, karena 
kualitas estetik dan motif. Dalam persepektif kultural, kearifan lokal dapat dikaitkan dengan masalah" identitas", konsep identitas dan strata realitas kebudayaan Batik Sri Tanjung adalah identitas budaya rumpun melayu.

\section{DAFTAR PUSTAKA}

Alwasiah. A. Chaedar. 2009. Pokoknya Kualitatif. Jakarta : Pustaka Jaya.

Alipuddin. 2010. "Ornamen Masjid Keramat Koto Tuo Pulau Tengah Kerinci Jambi” Tesis. ISI Padang Panjang

Dharsono, 2006. "Pohon Ayat

Sim-bol dan Makna Pohon

Hayat yang Terlukis pada

Batik Kla-sik sebagai ekpresi

Kebuday-aan Jawa”.

Disertasi. ITB Bandung

Dharsono Sony Kartika, Nanang

Ganda Perwira. 2004.

Pengantar Estetika. Bandung: Rekayasa Sain. 2007. Estetika.

Bandung: Rekayasa Sains. 2016. Kreasi

Artistik Perjumpaan Tradisi

Modern Dalam Paradigma
Kekaryaan Seni. Surakarta: Citra Sain 2017. Seni Rupa

Modern. Bandung: Rekayasa Sain.

Deperindag RI, 2001. Katalog Batik Indonesia. Yogyakarta: Balitbang Industri Kerajinan dan Batik.

Djumena, Nian S. 1990. Batik dan Mitra. Jakarta: Djambatan.

Ginanjar, Suendro. 2010. “Analisis Pengaruh Inovasi Produk Melalui Kinerja Pemasaran Untuk Mencapai keunggulan Bersaing Berkelanjutan”. Tesis. Universitas Diponegoro

Hamzuri. 1994. Batik Klasik. Jakarta: Djambatan

https://www.youtube.com/ watch?v=A6t1rx49Bx4(1)

http://www.ayoriau.com/indragirihilir/produksi-batik-sejak-tahun-2010-hadi-berhasil-kembangkan-21-motif.html

http://bertuahpos.com/lifestyle/pnswajib-pakai-batik-inhil.html.

Koentraningrat. 1980. Pengantar Antropologi. Jakarta: P.D. Ak-sara 
Lukman Sinar, Tengku. 1993. Motif dan Ornamen Melayu. Medan: LPPSBM

Moleong, L. 2008. Metodologi Penelitian Kualitatif . Bandung: PT Remaja Ros Karya

Masrita, Jenni. 2016. "Estetika Tra-disional Ragam Hias Istana Raja Gunung Sahilan” Tesis. ISI Padang Panjang.

M. Zubir. 2013. "Ornamen Makam Ratus Nahrasiyah Di Kabu-paten Aceh Utara" Tesis. ISI Padang Panjang Maryaeni. 2005. Metode Penelitian Kebudayaan. Jakarta: Bumi Angkasa

Prasetyo, Anindito. 2010. Batik Karya Agung Warisan Budaya Dunia. Yogyakarta: Pura Angkasa.

Rahmayanis. 2016. "Estetika Ornamen Pada Masjid Jami' Pasar Usang Air Tiris Kabupaten Kampar Provinsi Riau". Tesis. ISI Padang Panjang
Suryajaya, Martin. 2016. Sejarah Estetika” Jakarta: Gang Kabel.

Soetarno. Kumpulan Berbagai Makalah. Surakarta: ISI Surakarta Press.

Suhersono, Hery. 2005. Motif Geometris. Jakarta: Gramedia.

Soedjono, 1997. Batik Lukis. Bandung: Rosda

Syarifuddin. 2015. "Estetika Batik Tabir di Pekanbaru Provinsi Riau". Tesis. ISI Padang Panjang.

Samsi. 2007. Teknik dan Ragam Hias Batik. Yogyakarta

Tim Sanggar Batik Barcode. 2010. Mengenal Batik dan Cara Mudah Membuat Batik. Jakarta: Kata Buku.

Wulandari, Ari. 2011. Batik Nusantara Makna Filosofis, Cara pembuatan dan Industri Batik. Yogyakarta: Andi. 